\title{
Quando o Estado mata: desafios para medir os crimes contra a vida de autoria de policiais'
}

\author{
Samira Bueno* (D) \\ Renato Sérgio de Lima** (1) \\ Arthur Trindade Maranhão Costa ${ }^{* * *}$ (1)
}

\section{Resumo}

O artigo discute os processos e taxonomias utilizadas para classificar os episódios de homicídios praticados por policiais no Brasil, utilizando como estudo de caso o estado de São Paulo. Trata-se de um esforço de diálogo entre os campos da sociologia da segurança pública e o da sociologia da quantificação aliado ao estudo empírico da produção e uso de estatísticas criminais por parte das instituições que compõem o sistema de justiça criminal e segurança pública do Brasil. O objetivo, aqui, é relatar como a disputa em torno das mortes decorrentes de intervenções policiais está inserida em uma disputa maior sobre o sentido das políticas de segurança pública, e que as nomenclaturas adotadas consistem em táticas que buscam garantir a legitimidade do uso da força letal pelas polícias. A criação de múltiplas categorias para mensurar o resultado morte em decorrência da atividade policial e sua contabilização apartada dos homicídios dolosos constituem estratégia que turva a compreensão completa do significado dessas ocorrências e revela o quanto a opacidade ainda está presente, no país, na forma de governar e responder às demandas por mais eficiência no controle do crime e na manutenção da ordem pública.

Palavras-chave: Polícia, estatísticas, letalidade, homicídio, violência.

\footnotetext{
1 Este artigo é desdobramento atualizado do capítulo da tese de doutorado de Samira Bueno, que investigou o uso da força letal pela Polícia Militar no Estado de São Paulo e que, em seu capítulo 4, discutiu as diferentes taxonomias adotadas pelo governo para justificar uma intervenção policial que resultou na morte de um civil (Bueno, 2018).
}

* Fórum Brasileiro de Segurança Pública, São Paulo, SP, Brasil.

** Fundação Getúlio Vargas, São Paulo, SP, Brasil.

*** Universidade de Brasília, Brasília, DF, Brasil. 


\section{When the State kills: challenges to measure crimes against life by police}

\section{Abstract}

The article discusses the processes and taxonomies used to classify homicides practiced by police in Brazil, taking the state of São Paulo as a case study. Based on an empirical study about the production and use of criminal statistics by institutions that constitute the criminal justice and public security systems in Brazil, the article brings some reflections in dialogue between the fields of sociology public security and sociology of quantification. The objective here is to demonstrate how the dispute over deaths resulting from police interventions is part of a larger dispute over the meaning of public security policies, and that the adopted nomenclatures consist of tactics that seek to guarantee the legitimacy of the use of lethal force by the police. The creation of multiple categories to measure the result of deaths perpetrated by police officers and their registration apart from intentional homicides is a strategy that obscures the complete understanding of the meaning of these occurrences and it reveals how much opacity is still present, in the country, in the way of governing and responding to demands for more efficiency in controlling crime and maintaining public order.

Keywords: police, statistics, lethality, murder, violence.

\section{Introdução}

produção e utilização sistemática de estatísticas criminais no Brasil
remonta à década de 1870 , quando, em 1871, foi promulgada a
Lei 2.033 que, pela primeira vez, obrigava as províncias do país a produzirem e se submeterem a um mesmo padrão de classificação de registros de crimes. Naquele período, marcado como de burocratização, especialização e institucionalização do controle social, a produção de estatísticas criminais tornou-se um eixo estratégico de manutenção de governos e de poder; tornou-se insumo para a garantia de espaços opacos e discursos de verdade das instituições (Lima, 2005). De lá para cá, ao contrário de serem fruto de um processo burocraticamente racional e organizado, conectado às opções político-institucionais sobre regimes de 
Estado e de Governo e/ou aos novos formatos do pacto federativo brasileiro, os dados sobre crimes e criminosos continuaram a ser produzidos em grandes volumes, por diferentes órgãos e fontes, mas quase sem nenhuma coordenação entre as agências encarregadas de manter a ordem pública e prover segurança.

Os 150 anos de produção de dados policiais e criminais não foram capazes de romper com as noções de que estatísticas são meros subprodutos técnicos da ação das instituições de Estado e, por isso, isentas na descrição da realidade, e de que decisões sobre formulação e implementação de políticas criminais devem ser pensadas mais pela "experiência" das burocracias em como lidar com crimes, criminosos e violência. Diante desse fato, nota-se uma dissonância entre a produção e o uso de dados criminais, a qual distancia o registro estatístico e sistemático de ocorrências policiais de perspectivas que assumam, por exemplo, a transparência e a divulgação de dados como pressupostos estratégicos para a democratização das instituições de segurança pública e justiça criminal. Dissonância esta que estaria fundada não apenas na não publicização de dados que são burocraticamente produzidos, mas também na operação de um complexo sistema de equivalências morais e legais que pode revelar o papel da violência nas disputas políticas acerca das concepções de lei e ordem que regem as políticas de segurança pública no Brasil (Lima, 2019).

Para tentar aprofundar este debate, o presente artigo buscará detalhar, a partir do estudo do caso do estado de São Paulo, a forma de classificação e mensuração dos registros de mortes decorrentes de intervenções policiais, visando, com base nesse detalhamento, jogar luz sobre como categorias, nomenclaturas e tipologias traduzem, na prática, as referidas disputas acerca do significado de lei e ordem. Isso porque, se a essência do mandato policial reside no exercício do poder coercitivo autorizado pelo respaldo da força física de forma legítima e legal (Muniz; Proença Jr.; Diniz, 1999), a distinção entre o uso da força legítima e ilegítima permanece como um desafio para nações democráticas. Para muitos, polícia matar é sinônimo de eficiência no combate aos criminosos e, portanto, quanto mais mortes 
decorrentes de intervenção policial existirem, mais socialmente legitimados os padrões policiais estariam por gerar tal efeito. E, em sentido contrário, a legitimidade do uso da força não recairia na maior quantidade de mortes provocadas, mas no controle da violência pautado na cidadania e na preservação da vida. Nesse sentido, mensurar episódios fatais envolvendo policiais é apenas uma das formas de visibilizar a discussão sobre as bases sociais da legitimidade do uso da força por parte das instituições policiais.

Em outras palavras, o pressuposto aqui assumido é que a produção de indicadores e estatísticas não é, portanto, um processo isento ou imparcial. A produção de qualquer dado ou registro administrativo é feita por pessoas que agem coletivamente, refletindo necessariamente a sua interpretação acerca de determinada realidade (Becker, 1963). Assim, a opção em relação ao que mensurar é necessariamente uma escolha da política e/ou da burocracia, por conseguinte, os registros oficiais sempre informarão uma verdade construída pelo governo em relação a determinado tema. Não à toa, para fins analíticos, utilizaremos o indicador considerado como de maior confiabilidade e comparabilidade no campo da criminologia e justiça criminal, que é o crime contra a vida. Afinal, apesar das diferentes tipificações penais de cada país, o homicídio doloso produz prova irrefutável de um crime - o corpo -, o que em tese seria relativamente fácil de ser mensurado para qualquer governo, além de ser fenômeno normalmente monitorado por mais de um sistema ou área da gestão pública (Kahn, 2014). Não obstante esse fato, há diferentes formas de monitorar homicídios e mortes. No caso dos registros criminais, especificamente, isso se mostra ainda mais complexo, na medida em que não há consenso sobre quais eventos configuram crimes e transgressões, e, por consequência, quem é o criminoso. Ou seja, se o conceito de crime - e a definição do sujeito criminoso - é uma construção social, é justamente essa definição que vai pautar a decisão sobre quais dados coletar e quais fenômenos merecem ser monitorados (Ratton Jr., 1996).

Por essa perspectiva, o presente artigo busca aproximar a sociologia da violência e da segurança pública da sociologia da quantificação. É uma 
contribuição da análise das políticas de segurança pública para o debate da sociologia da quantificação e, assim sendo, suas referências e/ou, mesmo, suas lacunas ou reiterações precisam ser compreendidas. E, para fazer isso, o texto dialoga com a tradição dos estudos clássicos da sociologia da violência, mas reconhece que ainda são raros os estudos sobre os papéis político-institucionais dos dados e como eles revelam opções sobre modelos de controle da ordem e a aceitação da violência no Brasil, a exemplo do estudo de Lima (2019) e, mais recentemente, Bueno (2018).

Entre os estudos do campo da sociologia da violência, um marco é o estudo de Paixão (1987), desenvolvido como reflexão do trabalho na Fundação João Pinheiro, em Minas Gerais, a respeito dos indicadores sociais de criminalidade. Para este estudo, por trás de uma "aparência positivista" do acompanhamento de índices e taxas, há uma preocupação política importante com a forma de gerenciamento das instituições estatais e com o controle do poder por elas exercido. Daí a necessidade, para Paixão, de monitorar as diversas etapas e momentos em que o estado exerce o controle social e, a partir disso, visualizar os mecanismos de seleção e discriminação próprios das estruturas autoritárias. Com base em reflexões de Edmundo Campos Coelho (1986) e de Alba Zaluar (1985), o autor analisa a existência de lacunas nos dados como o reflexo da ausência de política sistemática de controle da criminalidade, mas também como ausência de uma política de transparência das ações estatais.

Por certo, tais assertivas estão em muito influenciadas pelo momento social em que o autor escrevia, ou seja, um momento em que cresciam as dificuldades em promover a democratização das instituições ligadas ao controle social e ao combate da criminalidade em paralelo ao crescimento da criminalidade urbana. Nessa reconfiguração da cena do crime e da violência no Brasil, Paixão foi um dos pioneiros a perceber que estávamos diante de um grande e fértil solo para o refortalecimento de demandas conservadoras e de endurecimento das políticas de controle, bem como de legitimação de ilegalismos como violências privadas, violência policial. Era o momento em que surge a necessidade de mapear com maior precisão 
o impacto real do crime, diferenciando-o do contexto cultural implicado no crescimento da violência urbana. Nesse aspecto, Paixão faz parte de um grupo de pesquisadores preocupados em diferenciar as ocorrências reais dos crimes das representações sociais sobre as razões do aumento do crime, do medo da violência, e da ideologia do combate ao crime que foi sintetizada na frase "bandido bom é bandido morto". Assim, ele atribui à ausência de informações contínuas, sistemáticas e comparáveis o distanciamento do cidadão do controle democrático da atuação das instituições e a permeabilidade das instituições a mecanismos informais de "inteligência organizacional", resultando em ilegalismos. Paixão chama a atenção para o fato de que estatísticas e dados oficiais são produtos organizacionais, que fazem sentido como indicadores sociais apenas na medida em que são analisados de forma combinada entre si, permitindo identificar os vieses organizacionais implicados em sua produção (Paixão, 1987).

Entretanto, Paixão (1987) não considera - talvez ele mesmo influenciado pelo positivismo em torno dos números - que as ausências são sociologicamente evidências que precisam ser contempladas em qualquer modelo analítico mais denso. Para esse empreendimento, os temas tratados originalmente pelo autor, que revelam como a estatística foi se tornando uma ciência de Estado, têm sido mais explorados pela sociologia da quantificação. Nesse outro campo de saber, o quantificar virou tema de reflexão autônoma a partir da década de 1990, a exemplo dos estudos de Alain Desrosières (1998; 2001), Bruno Latour (2004), lan Hacking (1991) e Kevin Haggerty (2001), que chamaram atenção para alguns aspectos teóricos fundamentais acerca da intersecção entre produção e uso de dados, em especial aqueles sobre os "centros de cálculos" que, para Latour (2004), correspondem aos espaços encarregados de coordenar a transformação de dados em agregados estatísticos que sirvam ao governo do Estado e da sociedade.

A sociologia da quantificação destacará que, conforme síntese desses autores fundantes da sociologia da quantificação feita por Lima (2005), as estatísticas não são desprovidas de ideologia e retroalimentam 
o funcionamento e os interesses da burocracia de Estado, que é, por sua vez e em última instância, a responsável pela produção das estatísticas e por determinar não somente regras administrativas, mas classificações e critérios de seleção de prioridades de governo (Hacking, 1991). O problema, portanto, estaria nos parâmetros e os objetivos por detrás das classificações, os quais, no limite, traduziriam a gramática e a linguagem do poder. Em complemento, para Alain Desrosières (1993), o objeto e as nomenclaturas da estatística enquanto ciência de Estado formam uma linguagem convencional de referência, cuja existência permite que um certo espaço público se desenvolva, mas cujo vocabulário e sintaxe podem ser colocados em debate. Para esse autor, as convenções de equivalência e permanência dos objetos que fundam a prática estatística são, elas também, o produto de investimentos políticos, sociais e técnicos que precisam ser observados

Nessa perspectiva, segundo Nelson Senra (2000), precisamos compreender quem oferece as estatísticas e como esse processo é realizado, numa discussão sobre o possível em contraponto ao desejável e que será conduzida na esfera de "centros de cálculo". Estes últimos - um conceito já mencionado anteriormente - nas palavras de Haggerty (2001), funcionam como um recurso de poder no âmbito do qual serão discutidas as nomenclaturas e as técnicas utilizadas no levantamento dos registros estatísticos, determinando, assim, os discursos que melhor amparem as estratégias de dominação estabelecidas e estabelecendo os regimes de verdades institucionais que serão disseminadas.

Este é o objetivo deste artigo. Analisar como a produção e o uso de dados sobre homicídios em geral e mortes decorrentes de intervenções policiais, em particular, estão conectados com a lógica em uso de funcionamento das instituições de segurança pública e com as disputas em torno do sentido e da agenda das políticas de segurança nos pós-1988, cujo foco se desloca de uma segurança pública voltada à defesa do Estado para uma segurança pública destinada a garantir direitos civis e sociais de cidadania. Assim, o artigo está dividido em cinco partes, incluindo esta introdução. Na segunda parte apresentamos a comparação entre os dados de homicídios praticados 
por policiais² do SIM/Datasus e os coletados pelo Fórum de Segurança Pública junto às instituições policiais, apresentando as diferenças entre os sistemas de informação. Na terceira parte é introduzida a discussão sobre as diferentes nomenclaturas utilizadas pelas polícias no Brasil para classificar um caso de morte em decorrência de intervenção policial, assim como as disputas envolvidas. Na parte quatro apresentamos o estudo de caso a partir dos registros de letalidade policial no Estado de São Paulo, bem como as diferentes nomenclaturas adotadas entre os anos 1990 e 2019. A última parte traz a conclusão, com a reflexão sobre as disputas políticas e simbólicas envolvidas em torno do contar os homicídios praticados por policiais e suas conexões com as disputas em torno do sentido da segurança pública e do controle social.

\section{O desafio de medir as mortes provocadas pelo Estado: comparando os registros do sistema de saúde e de segurança pública}

O primeiro esforço de consolidação de uma base de estatísticas criminais no mundo ocorreu no Congresso Geral de Estatística, realizado em Bruxelas em 1853, proposta que seria reiterada no Congresso Internacional sobre Prevenção e Repressão ao Crime, organizado em Londres em 1872 (FBSP, 2016). Naquele momento, justificava-se a coleta de estatísticas criminais em função da ideia de se buscar as causas do crime, o que foi mudando ao longo do século XX. Como resultado, diferentes projetos de sistematização de indicadores criminais passaram a ter como foco os sistema de justiça penal, o que contou com grande influência das Organização das Nações

${ }^{2}$ Ao longo deste artigo os episódios envolvendo a ação de policiais que resultam em morte serão tratados como homicídios de autoria de policiais, mortes em decorrência de intervenção policial e letalidade policial, sendo que as três nomenclaturas caracterizam um mesmo fenômeno: boletins de ocorrência oficialmente registrados pelas autoridades policiais e que indicam um agente estatal da ativa como o autor de um caso que resultou em morte, independentemente se em serviço ou fora. Esses episódios não incluem chacinas e execuções sumárias, e sim aqueles casos que envolvem o reconhecimento do excludente de ilicitude. 
Unidas (ONU) que tem dentre suas missões ajudar os governos na gestão da justiça criminal (FBSP, 2016). Mas só os registros policiais não são suficientes. O Crime Trend Survey (CTS), maior projeto de criminologia comparada do mundo, é conduzido pela ONU e levanta, desde a década de 1970, indicadores de criminalidade em vários países. No caso dos homicídios, o CTS trabalha com duas fontes de registros administrativos, aqueles produzidos pelos sistemas da área da saúde pública e os produzidos pelo sistema de justiça criminal e segurança pública. Isso porque o campo da saúde pública conta com um eficiente sistema padronizado de classificação internacional de doenças, consolidado na Classificação Internacional de Doenças da Organização Mundial de Saúde, atualmente em sua décima edição (CID-10).

No Brasil, cabe ao Sistema de Informações sobre Mortalidade do Ministério da Saúde a consolidação de estatísticas epidemiológicas e, em uma aproximação com as estatísticas de crimes contra a vida, é o capítulo sobre causas externas de mortalidade que consolida as categorias que podem ser equiparadas aos homicídios e outras mortes violentas intencionais. Já no campo da segurança pública e justiça criminal, o Escritório da ONU para Crimes e Drogas é o responsável, por sua vez, pela consolidação da Classificação Internacional de Delitos para Fins Estatísticos, aprovada na 46 $6^{\underline{a}}$ sessão da Comissão de Estatística das Nações Unidas, em março de 2015, e pela Comissão de Prevenção ao Crime e Justiça Criminal, em sua 24⿳亠口了 sessão, em maio de 2015, como um padrão estatístico internacional para coleta de dados.

A adequação à Classificação Internacional de Delitos para Fins Estatísticos ocorreu no Brasil através da portaria no 229, ${ }^{3}$ de 10 de dezembro de 2018, publicada pelo então Ministério da Segurança Pública. Segundo a portaria, o objetivo é "unificar e padronizar as classificações e o envio de dados pelos entes federados a serem implementados e fornecidos pelo

3 BRASIL. Portaria no 229, de 10 de dezembro de 2018. Disponível em: https://www. in.gov.br/materia/-/asset_publisher/Kujrw0TZC2Mb/content/id/54520504/do1-2018-12-11portaria-n-229-de-10-de-dezembro-de-2018. 
Sistema Nacional de Informações de Segurança Pública, Prisionais e de Rastreabilidade de Armas e Munições, de Material Genético, de Digitais e de Drogas - Sinesp". ${ }^{4}$ Apesar de o Estado brasileiro ter aderido à classificação da ONU, sua implementação ainda parece longe de ser realidade.

Em um país federativo, e em uma área que tradicionalmente não conta com coordenação federal (Lima, 2019), cabe a cada unidade federativa o registro e sistematização de seus indicadores de criminalidade, o que é feito pelas polícias estaduais, em especial pela Polícia Civil. Criado em 2012, o Sistema Nacional de Estatística em Segurança Pública - SINESP até hoje não se consolidou como um sistema de atualização periódica dos dados, ${ }^{5}$ o que ocorre apenas pela ação da sociedade civil organizada. Desde 2006, o Fórum Brasileiro de Segurança Pública (FBSP) cumpre esse papel, a partir da coleta, via Lei de Acesso à Informação, junto às instituições estaduais, e através da publicação do Anuário brasileiro de segurança pública. Entretanto, mesmo com a importância da ação da sociedade civil organizada em dar transparência aos obscenos números da violência letal registrados anualmente no Brasil, compreender o que decorre após estes crimes permanece um desafio.

Os registros de mortalidade provocada por agentes do Estado constituem um dos principais exemplos sobre o desafio de definir denominadores sobre o que e como se contam tais fenômenos. Para começar, a categoria "intervenção legal" na saúde é muito frágil, o que dificulta significativamente a utilização desse sistema para a medição do fenômeno. A Classificação

${ }^{4}$ O Sistema Nacional de Informações de Segurança Pública, Prisionais e sobre Drogas (SINESP) foi criado formalmente pela lei 12.681 de 4 de julho de 2012, tendo por objetivo regulamentar o processo de coleta, análise, atualização e sistematização das estatísticas criminais produzidas pelas Unidades da Federação. A lei do Sinesp foi alterada pela lei 13.675 de 11 de junho de 2018, que criou o Sistema Único de Segurança Pública (SUSP) e a Política Nacional de Segurança Pública e Defesa Social. Com a alteração, o Sinesp passa a ter também o caráter de acompanhamento e avaliação das políticas implementadas pelos entes federados - pelo menos formalmente -, além de incluir o banco de dados de perfil genético e digitais.

${ }^{5} \mathrm{O}$ Sinesp não divulga, por exemplo, estatísticas relativas às mortes por intervenções policiais, que respondem por $13,3 \%$ de todas as mortes violentas intencionais segundo dados do último Anuário brasileiro de segurança pública (FBSP, 2020). 
Internacional de Doenças (CID 10) define essa categoria como reservada para casos de conflitos armados e, tradicionalmente, ela é vista como reservada para registro de operações de guerra, havendo, por parte dos médicos que preenchem as declarações de óbito que são a base para os dados, certa resistência em assumir ações policiais que resultam em morte como operações de conflitos armados. Assim, a comparação entre os registros coletados pelo sistema de saúde e os compilados pelo FBSP, cuja fonte primária são os boletins de ocorrência policial, indica a enorme divergência entre os sistemas. Em 2019, os dados da segurança pública mostraramse $333 \%$ superiores aos registrados pela saúde que indicam tendência de queda, ao passo que os registros de segurança pública demonstram crescimento do fenômeno desde que passaram a ser coletados em 2013, conforme indica o gráfico 1.

Gráfico 1- Mortalidade provocada por policiais no Brasil - comparação entre sistemas da saúde e segurança pública

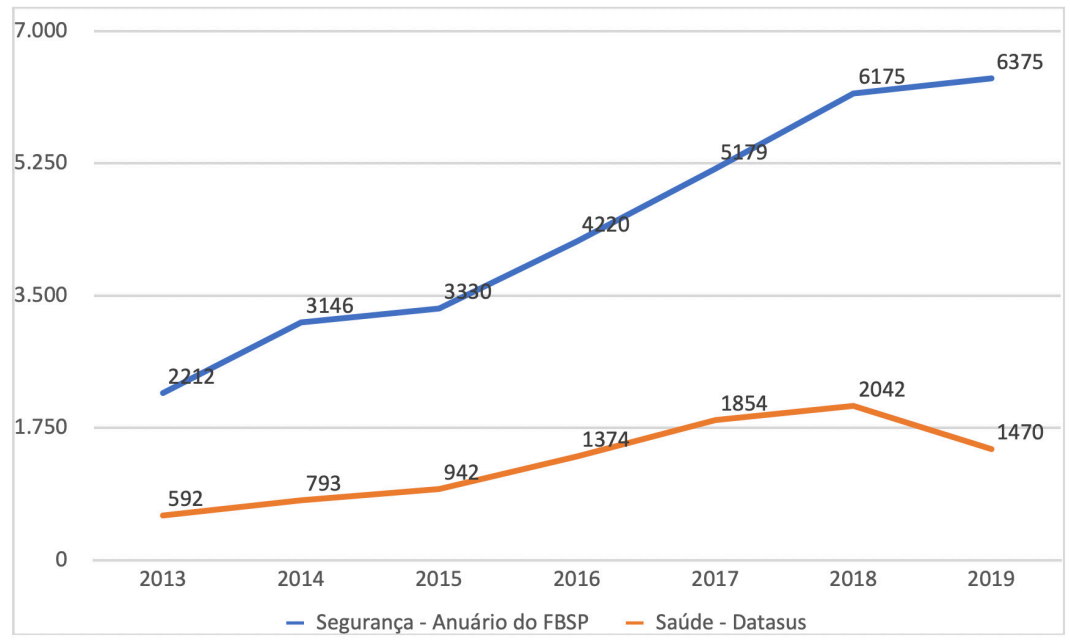

Fonte: SIM/Datasus; Anuário brasileiro de segurança pública (2020). 
Vale ressaltar que a Segurança Pública e a Saúde têm metodologias diferentes para contar mortes, uma vez que refletem os objetivos e as condições de produção de cada área. O sistema de justiça criminal quer saber se existiu um crime, como ele pode ser classificado juridicamente, se ele foi intencional, qual a motivação, como foi praticado e outras informações que permitam a identificação e punição do autor. Sua finalidade é jurídica e de instrução da persecução penal. A saúde quer saber a causa biológica da morte, os meios utilizados, o perfil da vítima, o contexto em que ocorreu e outras informações de cunho epidemiológico que sirvam para criar políticas preventivas (Kahn, 2014). O foco, neste caso, é o fenômeno de uma pessoa matar outra, que, a depender do contexto, tem diferentes tipificações penais possíveis na segurança. Cada sistema estatístico refletirá, portanto, as preocupações pertinentes ao seu universo e nenhum deles é necessariamente superior a priori. No caso das mortes por intervenções policiais, importa menos para o sistema de saúde a autoria, o que justifica a diferença, como já mencionado anteriormente. A questão é que, independentemente das diferenças metodológicas, a comparação entre as fontes deveria resultar em congruência e se espera que a magnitude do fenômeno seja aproximadamente a mesma, de modo que os locais apontados como mais violentos por uma deveriam coincidir com os locais indicados pela outra, e assim por diante. Isso ocorre quando somamos as mortes por agressão às intervenções legais e comparamos com as mortes violentas intencionais, mas não quando desagregamos as mortes que decorrem da ação dos agentes estatais.

Essa incongruência coloca um enorme desafio às políticas públicas de redução da violência, já que mensurar as mortes provocadas por agentes estatais tem dependido exclusivamente dos registros policiais e, mesmo neste sistema, entender a frequência desse fenômeno não é exatamente uma tarefa simples. Em uma reiteração, as opções institucionais e burocráticas por trás dos registros oficiais revelam muito mais do que a existência de uma vítima cuja morte foi provocada por um policial; revelam valores e 
moralidades que determinam qual nomenclatura esta ocorrência vai assumir, como essa narrativa será construída e quem é vítima da ação policial.

\section{A tipificação da letalidade da polícia nos boletins de ocorrência}

No Brasil, a letalidade produzida pelas polícias em geral assume a nomenclatura de "auto de resistência" ou de "morte por oposição à intervenção policial" nos boletins de ocorrência. Os autos de resistência não constituem um tipo criminal específico, são na realidade crimes de homicídio - tipificados no artigo 121 do Código Penal (CP) - teoricamente praticados com "exclusão de ilicitude". Segundo o artigo 23 do CP, não existe crime se o agente o pratica em estado de necessidade, em legítima defesa ou em estrito cumprimento de dever legal/no exercício regular de direito.

No Brasil, a nomenclatura adotada nesses casos é objeto de disputa antiga entre as polícias e movimentos de direitos humanos. A sociedade civil organizada sempre argumentou que as nomenclaturas "resistência seguida de morte" e "auto de resistência", comumente utilizadas nos registros policiais até 2012, partiam do princípio de que a vítima da ação letal era, desde o início da ocorrência tratada como criminosa, dado que teria resistido a uma determinação do Estado, e, por conseguinte, criminalizada a priori (Misse et al., 2013). Em função das pressões exercidas, a Secretaria Especial dos Direitos Humanos (SDH) da Presidência da República determinou a Resolução n. 8, de 20 de dezembro de 2012, que recomendava a abolição das designações "resistência seguida de morte" e "autos de resistência" nos registros policiais, recomendando o uso de "homicídio decorrente de intervenção policial" (Bueno, 2014).

Em reação a esta medida, o Conselho Superior de Polícia, vinculado ao Ministério da Justiça, e o Conselho Nacional dos Chefes de Polícia Civil divulgaram a Resolução Conjunta n. 2, de 13 de outubro de 2015, determinando a adoção de "homicídio decorrente de oposição à intervenção policial" nos casos de mortes de autoria de policiais, retomando a ideia da 
resistência no registro oficial. Mais do que uma questão simbólica, a medida responde a uma reinvindicação das polícias de todo o país em relação ao que significa o uso da força letal perpetrado pelos agentes estatais e sua não inclusão no rol de crimes.

A ideia central neste debate é que o policial não mata e tampouco é um homicida, apenas responde a uma ação de um criminoso com a força que julgou adequada e, por ser o representante da lei e possuir fé pública, esta não pode ser configurada crime. O fato de as vítimas das ações policiais serem quase que exclusivamente do sexo masculino, jovens, majoritariamente negros ${ }^{6}$ e residentes das periferias reforça esse argumento, já que são construídos como sujeitos matáveis. Caracterizados como moralmente condenáveis, perigosos e criminosos, as vítimas da ação policial constituem sujeitos a quem se reservam as piores punições (Misse, 2010). Nesse sentido, o controle do uso da força policial é ainda mais difícil porque, não raro, o arbítrio e a violência estatal contam com a anuência - ou mesmo com a demanda - da população, que vê no castigo físico aplicado ao desviante uma forma de justiça (Oliveira, 2010; Machado; Noronha, 2002). Sua morte, portanto, não é apenas aceitável, mas muitas vezes desejável.

Essa perspectiva, no entanto, não é exclusividade do contexto brasileiro. Sherman e Langworthy (1979) mostraram em estudo realizado na década de 1960 que uma das dificuldades relacionadas à contabilização de homicídios praticados por policiais nos Estados Unidos se deve justamente ao fato de a maioria da população acreditar que essas ocorrências não eram crime. Isso foi verificado por meio de um survey de 1969, no qual 57\% da população afirmava que ocorrências com "vítimas de tiros da polícia" não deveriam ser consideradas crime. Diante desse impasse, e de ao menos quatro diferentes fontes para tentar mensurar o fenômeno - registros de óbitos, registros

${ }^{6}$ Dados do último Anuário brasileiro de segurança pública (2020) demonstram que as Polícias Civil e Militar vitimaram 6.375 pessoas em 2019. Destas, 99,2\% eram do sexo masculino, $79,1 \%$ eram negras, e $74 \%$ eram adolescentes ou jovens com no máximo 29 anos. Disponível em: https://forumseguranca.org.br/wp-content/uploads/2021/02/anuario2020-final-100221.pdf 
policiais, relatórios do FBI e matérias de jornal -, os autores concluíram que todas as fontes possuíam significativas limitações.

Quatro décadas após a publicação do artigo, a contabilização das mortes provocadas por policiais permanece um desafio nos EUA e projetos jornalísticos, como o "The Counted" do jornal The Guardian (US edition) e o "Fatal Force" do The Washington Post, esforçam-se para monitorar e contabilizar todos os mortos em decorrência de ações de policiais em território estadunidense, contando essas histórias a partir de outras narrativas que não exclusivamente a versão policial. Assim como no Brasil, os casos de violência policial nos EUA atingem de forma desproporcional homens negros, indicando um padrão de seletividade em relação ao uso da força. Tanto o projeto do The Guardian quanto o do Washington Post encontraram no monitoramento jornalístico das vítimas números superiores à estatística oficial, registrada pelo $\mathrm{FBI}^{7}$

Do ponto de vista da Classificação Internacional de Crimes para Fins Estatísticas do Escritório da das Nações Unidas para Crimes e Drogas (UNODC, 2015), os registros oficiais deveriam diferenciar os casos em que o policial fez uso da força letal de forma apropriada daqueles em que houve uso excessivo da fora. Segundo o UNODC, quando se verifica que o policial fez uso da força letal de forma necessária e para proteção da vida, o registro estatístico deve assumir a nomenclatura morte decorrente de intervenção policial (death due to legal interventions), conforme explicação a seguir:

A morte decorrente de intervenção legal refere-se à morte infligida a uma pessoa pela polícia ou por outros agentes responsáveis pela aplicação da lei, incluindo militares em serviço, no decurso de uma prisão ou tentativa de prisão, de infração de leis, suprimindo distúrbios, manutenção da ordem e outras ações legais em que o uso da força pelo agente responsável pelo

\footnotetext{
${ }^{7} \mathrm{O}$ FBI contabiliza os registros de justifiable homicides, definido como "a morte de um criminoso por um agente da lei no cumprimento do dever legal", mas nem todas as polícias informam sua contagem anual de homicídios tidos como justificáveis, tornando a contabilidade oficial muito menor do que o número real. Os dados coletados pelo "The Counted" de homicídios praticados por policiais em 2015, por exemplo, mostraram-se $160 \%$ superiores ao número oficial divulgado pelo FBI.
} 
cumprimento da lei é necessário para proteger a vida (UNODC, 2015, p. 33, tradução nossa). ${ }^{\mathbf{2}}$

Já os casos em que se verificarem excessos e o policial usar da força letal além do necessário devem ser registrados como "morte resultante de excessivo uso da força por agente estatal", conforme depreende-se do trecho a seguir:

Homicídios causados pelo uso excessivo da força por agente estatal responsável pela aplicação da lei: a morte como resultado do uso da força por parte da lei ou de outros funcionários estaduais que excederam os limites estabelecidos por padrões nacionais e internacionais do que é estritamente necessário e exigido para o desempenho de seus deveres (UNODC, 2015, p. 33, tradução nossa). ${ }^{9}$

Verifica-se que, embora exista uma recomendação internacional, os conceitos são muito vagos e geralmente não explicitam o que é o uso desnecessário ou desproporcional da força letal, ou mesmo quando ele é necessário. O caráter subjetivo dessas ações também fica evidente nos documentos que regulam o uso da força pelas polícias, no âmbito da ONU e no Brasil. Isso torna ainda mais difícil a avaliação do público externo de qualquer ação com resultado morte envolvendo policiais.

Um detalhamento da forma como as 27 Unidades da Federação classificam as mortes decorrentes de intervenção policial fugiria do espaço e do escopo deste artigo. Assim, selecionamos um caso para aprofundamento, o do estado de São Paulo, onde as forças policiais respondem por $30 \%$ de todas as mortes violentas intencionais ocorridas no Estado, e que serve para ilustrar o desafio de medir a letalidade da polícia no Brasil.

8 "Death due to legal interventions refers to death inflicted upon a person by the police or other law-enforcement agents, including military on duty, in the course of arresting or attempting to arrest lawbreakers, suppressing disturbances, maintaining order, and other legal action when the use of force by law enforcement is necessary to protect life."

9 "Killings caused by excessive use of force by law enforcement: death as a result of the use of force by law enforcement or other state officials that exceeded the limits, set by national and international standards, of what is strictly necessary and required for the performance of their duty." 


\section{A produção de estatísticas sobre letalidade policial: o caso do estado de São Paulo}

A origem da produção e publicização oficial das estatísticas criminais no estado de São Paulo data de 1995, quando a Lei 9.155 foi aprovada, determinando que dados relativos a homicídios, vitimização e letalidade da polícia fossem publicados trimestralmente (São Paulo, 1995). Inicialmente, os registros de letalidade da polícia assumiram, no boletim de estatística trimestral, a nomenclatura de "resistência seguida de morte" e foram contabilizados apenas no caso de policiais que fizessem uso da força letal em serviço. Em 2000, a Resolução SSP 516/00 normatizou a produção de estatísticas relacionadas à letalidade e vitimização em ações policiais, incluindo os casos fora de serviço, homicídios dolosos e culposos (São Paulo, 2000). No ano seguinte, a Resolução SSP 161/2001 atualizou a regulamentação da previsão legal determinando a publicação dos dados a partir dos dois sistemas de coleta estabelecidos: o Sistema Estadual de Coleta de Estatísticas Criminais (Resolução SSP 160/2001), que trata dos dados criminais e operacionais e é alimentado pelas polícias Civil e Militar, e a Resolução SSP 516/2000, que trata dos dados sobre letalidade e vitimização em ações policiais, produzidos pelas corregedorias das duas polícias (São Paulo, 2000; 2001) .

As estatísticas de mortos por policiais no Estado de São Paulo é publicizada mensalmente, com base na resolução SSP 516/2000, pelas respectivas corregedorias, no Diário Oficial do Estado, 30 dias após o último caso resultante em morte do mês anterior. A dinâmica de produção dos dados oficiais de criminalidade no estado de São Paulo segue fluxos distintos, a depender da ocorrência. Nos casos de vitimização e letalidade policial, cabe às respectivas corregedorias gerar o dado oficial, que é encaminhado à Coordenadoria de Análise e Planejamento da Secretaria de Segurança Pública de São Paulo (CAP/SSP-SP), a instância responsável pelo fechamento das estatísticas oficiais para todas as demais ocorrências criminais. Ou seja, embora a CAP seja o órgão responsável pela produção 
de estatísticas criminais em todo o Estado, produzidas a partir dos boletins de ocorrência lavrados pela Polícia Civil, os casos envolvendo policiais como autores ou vítimas de homicídio são produzidos e contabilizados pelas próprias polícias, evidenciando as disputas em torno do que e de que forma deve ser contado.

Em relação aos registros de letalidade produzidos pela Polícia Militar, duas alterações importantes feitas ao longo do tempo precisam ser explicitadas para a correta análise da série histórica. Em 2006, uma nova categoria foi incluída no boletim de divulgação da Corregedoria da PM com a nomenclatura "homicídio doloso fora de serviço", que consiste, segundo os próprios documentos publicados, em "[...] reações de policiais militares com provável excludente de ilicitude (reações a roubo e tentativa de roubo)". Isso significa dizer que a PM criou três tipos de homicídio doloso em sua classificação estatística: 1) praticados por policiais em serviço, ou seja, casos em que se apurou que não houve o excludente de ilicitude; 2) praticados por policiais fora de serviço; e 3) praticados por policiais militares fora do horário de serviço, mas que consistiram na reação do policial à tentativa de assalto, resultando na morte do suspeito. Neste último caso, haveria a exclusão de ilicitude já que o policial o fez no "cumprimento do dever legal", ainda que na folga e, portanto, não deveria ser considerado crime. Ainda assim, esses casos não foram classificados como "resistência seguida de morte fora de serviço", que seria o equivalente à exclusão de ilicitude e que já constava como uma categoria do extrato de publicação.

No ano de 2013, uma nova resolução, a SSP 143, teve por objetivo disciplinar a inserção de dados no Sistema Estadual de Coleta de Estatísticas Criminais. Dentre outras ações, a resolução afirma, em seu artigo 5o, que "[...] os casos de Lesão Corporal Decorrente de Intervenção Policial e de Morte Decorrente de Intervenção Policial, bem como o cômputo de vítimas geradas dessas ações, deverão ser contabilizados apartadamente, em quadro próprio" (São Paulo, 2013). Já o seu parágrafo único afirma que "[...] diversamente, os registros de ocorrências de homicídios dolosos atribuídos a policiais em serviço ou fora de serviço, além de classificação 
própria na forma da Res. 516, serão contabilizados conjuntamente com os homicídios dolosos previstos na forma da Res. 160" (São Paulo, 2013).

Em 2015, uma nova alteração foi feita com a Resolução SSP 40/2015 e os casos classificados na categoria "homicídio doloso fora de serviço (*reações)" passaram a ser contabilizados como mortes decorrentes de intervenções policiais fora de serviço. Assim, a categoria "morte decorrente de intervenção policial fora de serviço", que aparecia zerada desde 2009, passa a ter dados a partir do segundo trimestre de 2015, enquanto a categoria "homicídio doloso fora de serviço(*reações)", criada pela Corregedoria da PM em 2006, deixa de ser utilizada. Para informar as mudanças, a Secretaria de Segurança incluiu em seu site uma nota metodológica afirmando que:

Até março de 2015, a Corregedoria da Polícia Militar utilizava uma categoria específica denominada "Homicídio doloso - fora de serviço (reações)", contabilizando somente os casos em que consideravam presentes excludentes de ilicitude. Eram excluídos, portanto, os homicídios dolosos e culposos. Esses dados sempre foram publicados no DOE, no último dia do mês seguinte da ocorrência dos dados. A partir de abril de 2015, a Polícia Militar adequou à exata classificação da Res. SSP 40/15, passando a contabilizar todos os casos de morte em decorrência de qualquer intervenção considerada lícita do policial militar em folga, inclusive os casos em que presentes as excludentes de ilicitude. Continuam excluídos os homicídios dolosos, inclusive "homicídios múltiplos" e culposos, que são contabilizados nos termos da Res. SSP $160 .{ }^{10}$

Na prática o que ocorreu foi a exclusão de uma categoria que só existia formalmente para a PMESP e, seus dados, ao invés de serem considerados homicídios fora de serviço com provável excludente de ilicitude, passaram a ser considerados como mortes decorrentes de intervenções policiais fora de serviço. Essa mudança metodológica teve dois impactos imediatos. De um lado, explicitou-se o entendimento da pasta da Segurança Pública em relação aos homicídios praticados por policiais fora do horário de serviço, retirando a ideia da intencionalidade contida no homicídio doloso e assumindo exclusivamente a legítima defesa; de outro, excluiu a categoria

${ }^{10}$ Disponível em: http://www.ssp.sp.gov.br/estatistica/plantrim/2015-03.htm 
que a Polícia Militar tinha criado exclusivamente para si, uma excrescência jurídica.

A questão de fundo neste debate metodológico sobre como nomear as ocorrências envolvendo policiais que resultam em morte é que, ao longo do período compreendido entre 2006 e 2015, 973 pessoas foram mortas por policiais militares em ocorrências que foram classificadas como "homicídios fora de serviço com provável excludente de ilicitude", nomenclatura que não foi absorvida pela estatística de homicídios dolosos e tampouco pela de letalidade policial.

Feitas, portanto, as ressalvas metodológicas e explicitados os limites do que as estatísticas contabilizam, refletimos aqui sobre duas variáveis fundamentais para a compreensão dessa aparente "confusão" na produção de estatísticas sobre a letalidade pela PMESP. A primeira diz respeito a uma reinvindicação das polícias militares de todo o país em relação ao que significa o uso da força letal e sua não interpretação de que constitui crime; a segunda refere-se ao impacto que teria nas estatísticas oficiais a contabilização desses casos dentro do total de homicídios dolosos.

Em relação ao primeiro ponto, é importante dizer que se trata de um debate antigo e que guarda relação com a criação do termo "resistência seguida de morte", nos anos de ditadura militar. Embora não exista enquanto uma categoria específica no Código Penal e se enquadre no conceito de homicídio doloso, esses casos são assim classificados para proteger o policial, já que, em teoria, o agente estatal tem a prerrogativa de uso da força letal se necessário. Verani (1996) afirma que o auto de resistência foi regulamentado em 1969 pela Superintendência da Polícia do então Estado da Guanabara, ${ }^{11}$ por meio da ordem de serviço no 803 , que determinou a dispensa de prisão em flagrante nos casos em que policiais fizessem uso da

11 Criado em 1960 e extinto em 1975, pelo regime militar, sem consulta popular, o estado da Guanabara ocupava o território da cidade do Rio de Janeiro, configurando-se como uma espécie de compensação desta por ter perdido a condição de centro político do país, com a transferência da sede do governo federal para a Brasília, construída na gestão do presidente Juscelino Kubistchek. 
força letal em operações. Em 1974 o secretário de Segurança Pública do Estado da Guanabara determinou, por meio de portaria, os procedimentos a serem adotados pela Polícia Civil para que os policiais envolvidos nos autos de resistência não fossem autuados em flagrante, focando sua argumentação na incriminação do suspeito morto pelos crimes cometidos e reforçando a legalidade da ação policial.

Sergio Verani, jurista e desembargador, foi um dos pioneiros nos estudos sobre letalidade policial ao mostrar em sua tese de doutorado que o sistema de justiça é conivente com a mortalidade provocada pela polícia, dado que o Poder Judiciário geralmente corrobora com a tese da legítima defesa dos policiais ao arquivar as investigações. Também sobre a anuência tácita do sistema penal em relação às ações letais produzidas pelas polícias, Zaccone (2015) afirma que os autos de resistência funcionam para a produção da verdade jurídica, um expediente burocrático e racional que viabiliza a ideia de uma violência conforme o direito, autorizada quando perpetrada por agentes públicos e referendada por promotores e juízes. O autor analisa 308 casos de auto de resistência seguida de morte na cidade do Rio de Janeiro e demonstrou que o arquivamento é quase regra.

A estratégia utilizada pelo governo de São Paulo indica que a criação de uma categoria própria na publicação de estatísticas para contabilizar homicídios praticados por policiais fora de serviço tendo como fulcro a legítima defesa parece ser uma das estratégias que busca legitimar ações fatais envolvendo policiais, já que se extingue a punibilidade da ação desde o momento do registro do boletim de ocorrência, tal como feito historicamente com o auto de resistência. A consequência direta dessa estratégia é o alargamento do conceito de excludente de ilicitude, geralmente utilizado para justificar casos no horário de serviço, mas que passa também a ser instrumentalizado para episódios no horário de folga desses policiais.

Outra consequência direta dessa estratégia, que cria uma série de categorias diferentes para mensurar um mesmo fenômeno, o homicídio de autoria de policial, é que, ao serem contabilizados de forma apartada, 
mortes provocadas por policiais não compõem o indicador de homicídio doloso do Estado. Para se ter ideia do que isso significa, se o número absoluto de homicídios dolosos caiu 77\% entre 2000 e 2019, as mortes provocadas por policiais apresentaram crescimento de 45,7\%.

\section{Conclusão}

O material empírico apresentado por este artigo sugere que a possibilidade de usar da força física, inclusive a letal, é elemento central para a compreensão do mandato policial e do que diferencia o agente estatal de um cidadão comum em todos os países ocidentais (Bueno, 2018). E, mais do que isso, no Brasil, explicita que diferentes formas de medir e classificar as mortes decorrentes de intervenção policial derivam de diferentes perspectivas de controle da ordem - uma ordem social democrática e com segurança pública como direito social universal, como previsto na Constituição Federal (CF), ou outras concepções de ordem mais próximas da ideia de defesa do Estado e da eliminação de inimigos internos, previstas em normas infraconstitucionais anteriores à CF e ainda hoje vigentes (Lima, 2019). Derivam também do grau de legitimidade que cada uma dessas formas confere a tais mortes e concebe a atividade policial. Isso porque o policial atua permanentemente em uma zona de ambiguidade, pois, ao mesmo tempo em que atua para garantir direitos e proteção, é responsável pela repressão. Contudo, a discricionariedade que o sistema legal the confere não pode ser confundida com arbitrariedade (Bretas; Poncioni, 1999). Assim, em termos de atividade policial, embora o agente detenha um poder discricionário, como um elemento inerente à sua função, este não deveria ser interpretado como um cheque em branco para definir quando cabe o recurso à violência em suas ações (Costa, 2004).

A questão é que, o que seria uma questão de limite legal, que poderia ser fixado a partir de parâmetros técnicos, é invisibilizado cotidianamente por microprocessos burocráticos e políticos. Não à toa, ao longo dos últimos 
trinta anos, diversos pesquisadores conseguiram demonstrar a persistência de práticas violentas das polícias no Brasil, ao apontar a impermeabilidade dessas organizações a reformas e controle externos e a permanência de práticas autoritárias no seu dia a dia de trabalho (Mingardi, 1992; Paixão, 1995; Bretas, 1997; Soares, 2000; Adorno, 1996; 2002; Zaluar, 1999), mas são poucos e recentes os estudos que avançaram no sentido de mensurar e coletar evidências empíricas sobre a letalidade produzida pelas polícias, caracterizando detalhadamente as vítimas e demonstrando sua distribuição espacial, racial e de gênero (Cano, 1997; Sinhoretto; Schlittler; Silvestre, 2016; Zilli, 2018; Ramos, 2020).

No limite, para o debate proposto no dossiê desta edição de Sociologias, a quantificação é feita, mas sem, necessariamente, conseguir mensurar fenômenos políticos opacos e associados aos aspectos mais amplos de organização da relação entre Estado e sociedade. Os aspectos técnicos metodológicos descritos mostram que, na linha sugerida por Haggerty (2001), o percurso aqui percorrido traz evidências de que muitas das questões postas hoje na definição dos rumos das políticas de segurança pública no país estão assentadas, também, na criação de múltiplas categorias para mensurar o resultado morte perpetrado por policiais e sua contabilização apartada dos homicídios dolosos. Ao fazer isso, o Estado, em suas múltiplas esferas e poderes, acaba por, tácita ou explicitamente, aceitar discursos que amparam uma concepção de ordem que legitima a violência como mecanismo de controle social de grupos socialmente indesejados e vistos como inimigos.

A dificuldade de mensuração do grau de letalidade policial em São Paulo seria resultado, portanto, da não existência de "centros de cálculo" capazes de estabelecer medidas que deem conta de visibilizar o fenômeno enquanto um fenômeno eminentemente político e social. Assim, ao contrário do que propugnam os estudos da área da segurança pública que apostam apenas no aperfeiçoamento da gestão das polícias, à semelhança de Paixão (1987), a questão não é meramente técnica e/ou de legitimação organizacional de 
categorias ou nomenclaturas mais abrangentes e que conseguissem incluir um retrato mais completo da ação policial. Esse esforço é importante e tem sido conduzido pela sociologia da violência e por entidades da sociedade civil como o Fórum Brasileiro de Segurança Pública, que criou, em 2015, a categoria "Mortes Violentas Intencionais", que tem sido adotada por vários órgãos públicos e centros de pesquisa por ser capaz de somar diferentes tipificações e nomenclaturas em torno do ato de uma pessoa matar outra, incluindo os casos envolvendo policiais. Porém, a não existência de tais "centros de cálculo" no âmbito público precisa ser pensada no rol das estratégias de manutenção de espaços opacos de reprodução de poder e de verdades organizacionais bastante refratárias às transformações inauguradas pela Constituição de 1988.

Nessa direção, o artigo mostra que a estatística (re)produz a legitimidade do uso da força letal que tem marcado a violenta história social brasileira. Isso porque, especificamente no caso de São Paulo, a manutenção da metodologia de aferição de tais mortes tem a ver com o fato de que muitas polícias resistem em admitir que sua prática tem resultado na morte de centenas de pessoas todos os anos. Para a corporação, seus policiais não matam, apenas reagem à ação de criminosos, ainda que produzam o resultado morte. O caso de São Paulo é sintomático das mudanças metodológicas e da criação de diferentes tipos de nomenclatura para qualificar uma ocorrência de homicídio cuja autoria é de policial, seja em serviço ou fora, mas que, no limite, buscam de todas as formas nomeá-la de modo a isentar os agentes estatais de qualquer punição pela ação letal. Considerando-se que resistência seguida de morte, morte por oposição à intervenção policial, morte decorrente de intervenção policial e homicídio com provável excludente de ilicitude são diferentes formas de caracterizar um mesmo fenômeno - a ação letal perpetrada por um policial - percebe-se que está em jogo a tentativa de dissociá-lo do dolo envolvido no homicídio.

Por este movimento, o ato de um policial matar outra pessoa, que, para efeitos legais não muda a tipificação penal deste fato como um homicídio, 
vira palco de estratégias de poder e saber que buscam obnubilar padrões operacionais e culturas organizacionais ainda muito marcadas pelo controle violento da ordem. Em termos jurídicos, tais estratégias desconsideram que um homicídio praticado por policial continua sendo um homicídio. Mas, se reconhecida sua legitimidade e configurada a excludente de ilicitude pelo cumprimento do dever legal após apreciação do caso pelo Ministério Público e pelo Poder Judiciário, ele teria sua punibilidade afastada e o policial não seria acusado de um crime. Ou seja, a polícia pode, no limite, matar, mas ela não pode, por si mesma, decidir sobre a legitimidade do ato e encerrar maiores consequências jurídicas e institucionais. E, para garantir esse espaço de autonomia, múltiplas categorias estatísticas são utilizadas para reforçar a invisibilidade do fenômeno e o tratamento abaixo da linha do radar das pressões por maior accountability e prestação de contas da parte das polícias brasileiras.

Essa é uma prática que, em si, tem sido bem analisado pela literatura. A tática que se esconde em torno do "como medir" o resultado morte produzido pelos policiais se soma a uma estratégia amplamente documentada pela literatura que busca transformar a vítima da ação policial em sujeito criminoso (Willis, 2013; Cano, 1997; Sinhoreto, Silvestre; Schlittler et al., 2014; Schlittler, 2016). Ainda no registro da ocorrência busca-se a desconstrução do elemento de cidadania da vítima e sua incriminação, transformando-a em autora de um crime (ou futuro crime), mas revestida da linguagem jurídica na tentativa de mostrar a objetividade dos operadores do sistema de justiça criminal em sua análise (Misse et al., 2013). Isso, evidentemente, encontra eco no imaginário social em torno do que vem a ser bandido ou elemento perigoso.

Verifica-se, portanto, que o significado do matar na ação policial é um tema em constante disputa dentro do campo da segurança pública e das organizações policiais. Enquanto segmentos das polícias reivindicam que esses casos não sejam assumidos como crimes, cada vez mais a imprensa, a universidade e os movimentos de direitos humanos têm questionado se os 
crescentes números de mortos por policiais não seriam indícios de desvios, abusos e execuções por parte dos agentes encarregados da manutenção da lei. E é justamente em função dessa disputa que, para as polícias, se faz necessário reforçar a sua legitimidade das mais diferentes formas, seja a partir de discursos que buscam ratificar a necessidade e proporcionalidade da ação policial, seja em suas interações com a sociedade pelas mídias sociais. Nesse contexto, adotam-se estratégias de legitimação pautadas por estatísticas, tidas como objetivas e reflexo da realidade, assim como o uso de atributos morais e moralizantes sobre os policiais e suas vítimas para justificar os feitos da corporação e garantir que sua estabilidade organizacional não seja afetada. Como agravante, se a produção seletiva de estatísticas sobre mortes decorrentes de intervenção policial é uma variável histórica, ela vem se somar ao tempo social de radicalização de posições e espaços de saber e poder de segmentos antidemocráticos e acaba por interagir com o intenso e acelerado processo de autonomização e politização conservadora das forças policiais no mundo e, especialmente, no Brasil, fenômeno sociológico de primeira grandeza do século XXI (Lima; Bueno, 2020).

A discussão feita aqui, portanto, conecta o debate dos campos das sociologias da violência e da quantificação visando, a partir da análise dos papéis político e institucional das estatísticas sobre mortes decorrentes de intervenções policiais, concluir que, para além dos alertas para os aspectos técnicos de modernização das polícias, que têm sido objeto de vários estudos da sociologia da violência, é fundamental o aumento da capacidade de governança democrática das instituições policiais, que passa por uma mais eficiente articulação e coordenação federativa. Esta, por sua vez, requer a explicitação dos papéis políticos dos dados e seus alinhamentos aos princípios e diretrizes emanados da nova ordem social nascida da nossa Carta Magna. Enquanto as instituições policiais forem operadas segundo a lógica do segredo, da opacidade e do reforço da violência como estratégia de controle social, pouco se conseguirá mudar no cenário do crime e da segurança pública no país. 
Samira Bueno é Doutora em Administração Pública e Governo pela Escola de Administração de Empresas da Fundação Getúlio Vargas (FGV-EAESP), diretora-executiva da ONG Fórum Brasileiro de Segurança Pública.

$\triangle$ sbueno@forumseguranca.org.br

Renato Sérgio de Lima é Doutor em Sociologia, Professor do Departamento de Gestão Pública da FGV EAESP. Diretor Presidente do Fórum Brasileiro de Segurança Pública.

$\triangle$ renato.lima@forumseguranca.org.br

Arthur Trindade Costa é Diretor do Instituto de Ciências Sociais da Universidade de Brasília, Coordenador do Núcleo de Estudos sobre Violência e Segurança (NEVIS/UnB) e Conselheiro do Fórum Brasileiro de Segurança Pública.

$\triangle$ arthurtmcosta@gmail.com

\section{Referências}

1. ADORNO, Sergio. A gestão urbana do medo e da insegurança. São Paulo, 281 p. Tese (Livre-Docência). Faculdade de Filosofia, Letras e Ciências Humanas da Universidade de São Paulo, 1996.

2. BECKER, Howard. Outsiders: studies in the sociology of deviance. Nova York: The Free Press, 1963.

3. BRETAS, Marcos Luiz. Observações sobre a falência dos modelos policiais. Tempo social, v. 9, n. 1, p. 79-94, 1997.

4. BRETAS, Marcos Luiz; PONCIONI, Paula. A cultura policial e o policial civil carioca. In: PANDOLFI, Dulce et al. (org.). Cidadania, justiça e violência. Rio de Janeiro: Fundação Getúlio Vargas, 1999.

5. BUENO, Samira. Bandido bom é bandido morto: a opção ideológicoinstitucional da política de segurança pública na manutenção de padrões de atuação violentos da polícia militar paulista. Dissertação. (Mestrado em Administração). Escola de Administração de Empresas de São Paulo. Fundação Getúlio Vargas, 2014.

6. BUENO, Samira. Trabalho sujo ou missão de vida? Persistência, reprodução e legitimidade da letalidade na ação da PMESP. Tese. (Doutorado em Administração Pública e Governo). Escola de Administração de Empresas de São Paulo da Fundação Getulio Vargas, 2018.

7. CANO, Ignacio. Letalidade da ação policial no Rio de Janeiro. Rio de Janeiro: ISER, 1997.

8. COELHO, Edmundo C. A administração da justiça criminal no Rio de Janeiro: 1942-1967. Dados: Revista de Ciências Sociais, Rio de Janeiro, v. 29, n. 1, p. 61-81, 1986. 
9. COSTA, Arthur T. M. Entre a lei e a ordem. Rio de Janeiro: FGV Editora, 2004. 10. DESROSIÈRE, Alain. How real are statistics? Four possible attitudes. Social Research, v. 68, n. 2, p. 339-356, 2001.

11. DESROSIÈRE, Alain. The politics of large numbers: a history of statistical reasoning. Cambridge: Harvard University Press, 1998.

12. FBSP - FÓRUM BRASILEIRO DE SEGURABÇA PÚBLICA. Estudo das classificações estatísticas e tipificações penais de mortes violentas nos compêndios internacionais e iniciativas federais. Projeto pesquisa e análise de dados vinculados ao campo da segurança pública e sistema penitenciário. São Paulo: FBSP, 2016.

13. HACKING, lan. How should we do the history of statistics? In: BURCHELL, Graham; GORDON, Colin; MILLER, Peter (eds.). The Foucault effect: studies in governmentality. Chicago: The University of Chicago Press, 1991. p. 181-196.

14. HAGGERTY, Kevin D. Making crime count. Toronto: University of Toronto Press, 2001.

15. KAHN, Tulio. Medindo a criminalidade: métodos, fontes e indicadores. São Paulo, 2014.

16. LATOUR, Bruno. Scientific objects and legal objectivity. In: POTTAGE, Alain; MUNDY, Martha (eds.). Law, Anthropology and the constitution of the social. Making persons and things, Cambridge: Cambridge University Press, 2004. p. 73-113.

17. LATOUR, Bruno. A esperança de Pandora. Bauru: EDUSC, 2001.

18. LIMA, Renato Sergio. Contando crimes e criminosos em São Paulo: uma sociologia das estatísticas produzidas e utilizadas entre 1871 e 2000. Tese. (Doutorado em Sociologia). Universidade de São Paulo, 2005.

19. LIMA, Renato Sergio. Segurança pública como simulacro de democracia no Brasil. Estudos Avançados, v. 33, n. 96, p. 53-68, 2019.

20. LIMA, Renato Sergio; BUENO, Samira. A tropa de choque de Bolsonaro. Piauí [online], 8 ago. 2020. Disponível em: https://piaui.folha.uol.com.br/tropade-choque-de-bolsonaro/

21. MACHADO, Eduardo P.; NORONHA, Ceci V. A polícia dos pobres: violência policial em classes populares urbanas. Sociologias, v. 4, n. 7, p. 188-221, 2002.

22. MINGARDI, Guaracy. Tiras, gansos e trutas: cotidiano e reforma na Polícia Civil. São Paulo: Editora Página Aberta, 1992.

23. MISSE, Michel; GRILLO, Carolina C.; TEIXEIRA, César P.; NÉRI, Natasha E. Quando a polícia mata: homicídios por "autos de resistência" no Rio de Janeiro (2001-2011). Rio de Janeiro: Booklink, 2013.

24. MUNIZ, Jacqueline; PROENÇA JÚNIOR, Domício; DINIZ, Eugênio. Uso de força e ostensividade na ação policial. Conjuntura Política - Boletim de análise. Belo Horizonte: Departamento de Ciência Política/UFMG, n. 6, abr. 1999. p. 22-26. 
25. NEME, Cristina. Nota sobre as estatísticas criminais do Estado de São Paulo. São Paulo, 14/11/2015. Lista de discussão Associados FBSP. Fórum Brasileiro de Segurança Pública, Brasil.

26. OLIVEIRA, Antonio. Os policiais podem ser controlados? Sociologias, v. 12, n. 23, p. 142-175, 2010.

27. PAIXÃO, Antônio Luiz. O problema da polícia. In: Violência e participação política no Rio de Janeiro. Rio de Janeiro: IUPERJ (Série Estudos, 91), 1995. p. 5-21,

28. PAIXÃO, Antonio L. Relatório de Indicadores Criminais. Relatório de Pesquisa. Belo Horizonte: Fundação João Pinheiro, 1987.

29. RAMOS, Sílvia (coord.). A cor da violência policial: a bala não erra o alvo. Relatório de pesquisa. Rio de Janeiro: Rede de Observatórios de Segurança/ CESeC, 2020.

30. RATTON JR., José Luiz. Violência e crime no Brasil contemporâneo: homicídios e políticas de segurança pública nas décadas de 80 e 90. Brasília: MNDH, 1996.

31. SÃO PAULO. Lei 9.155 de 1995. Dispõe sobre a obrigatoriedade da publicação trimestral das informações que especifica. Diário Oficial, Executivo, p. 1, 25 maio 1995.

32. SÃO PAULO. Resolução SSP 516/00. Secretaria de Segurança Pública, 15 dezembro 2000.

33. SÃO PAULO. Resolução 143 da Secretaria de Segurança Pública. São Paulo: Secretaria de Segurança Pública, 26 set. 2013.

34. SENRA, Nelson. Informação estatística: demanda e oferta, uma questão de ordem. DataGramaZero - Revista de Ciência da Informação, v. 1, n. 3, jun. 2000.

35. SHERMAN Lawrence W; LANGWORTHY, Robert H. Measuring homicide by police officers. Journal of Criminal Law and Criminology, v. 70, n. 4, p. 546-560, 1979.

36. SCHLITTLER, Maria Carolina. "Matar muito, prender mal". A produção da desigualdade racial como efeito do policiamento ostensivo militarizado em SP. Tese. (Doutorado em Sociologia). Universidade Federal de São Carlos, 2016.

37. SINHORETTO, Jacqueline; SILVESTRE, Giane; SCHLITTLER, Maria Carolina. Desigualdade racial e segurança pública em São Paulo: letalidade policial e prisões em flagrante. Sumário Executivo. São Carlos: Grupo de Estudos sobre Violência e Administração de Conflitos, 2014. Disponível em: http://www.ufscar. br/gevac/wp-content/uploads/Sum\%C3\%A1 rio-Executivo_FINAL_01.04.2014.pdf

38. SINHORETO, Jacqueline; SCHLITTLER, Maria Carolina; SILVESTRE, Giane. Juventude e violência policial no município de São Paulo. Revista Brasileira de Segurança Pública, v. 10, n. 1, p. 10-35, 2016. 
39. SOARES, Luís Eduardo. Meu casaco de general. Quinhentos dias no front da segurança pública. São Paulo: Cia. Das Letras, 2000.

40. UNODC - Escritório das Nações Unidas sobre Drogas e Crime. International classification of crime for statistical purposes, Version 1.0. Março, 2015.

41. VERANI, Sergio. Assassinatos em nome da lei: uma prática ideológica em nome do direito penal. Rio de Janeiro: Aldebarã, 1996.

42. WILLIS, Graham D. The killing consensus: homicide detectives, police that kill and organized crime in São Paulo, Brazil. 2013. Tese (Doutorado em Urban and Regional Studies). Massachusetts Institute of Technology, Dept. of Urban Studies and Planning, 2013.

43. ZACCONE, Orlando. Indignos de vida: a forma jurídica da política de extermínio de inimigos na cidade do Rio de Janeiro. Rio de Janeiro: Revan, 2015.

44. ZALUAR, Alba. Um debate disperso: violência e crime no Brasil da redemocratização. São Paulo em Perspectiva, v. 13, n. 3, p. 3-17, 1999.

45. ZALUAR, Alba. A máquina e a revolta. São Paulo: Brasiliense, 1985.

46. ZILLI, Luís Felipe. Letalidade e vitimização policial: características gerais do fenômeno em três estados brasileiros. Repositório do Conhecimento do IPEA, Instituto de Pesquisa Econômica Aplicada, 2018. 